\section{Screening the USDA Watermelon Germplasm Collection for Drought Tolerance at the Seedling Stage}

\author{
Haiying Zhang, Guoyi Gong, Shaogui Guo, Yi Ren, and Yong Xu' \\ National Engineering Research Center for Vegetables, Beijing Academy of \\ Agricultural and Forestry Sciences, No. 9 Shuguanghuayuan Road, Haidian \\ District, Beijing, 100097, China
}

\author{
Kai-Shu Ling \\ U.S. Department of Agriculture, Agricultural Research Service, U.S. Vegetable \\ Laboratory, 2700 Savannah Highway, Charleston, SC 29414
}

Additional index words. Citrullus lanatus, breeding, plant introduction

\begin{abstract}
Because of the growing threat of global warming, drought stress could severely affect the normal growth and development of crop plants. To alleviate such an adverse effect, there is a need to screen watermelon germplasm collections to identify genetic sources for potential drought tolerance. In the present study, 820 accessions of USDA's Citrullus PIs and 246 watermelon breeding lines were evaluated for their drought tolerance at the seedling stage under extreme water stress conditions in a greenhouse. Significant variations in drought tolerance were observed in the Citrullus germplasm collections. Using fast clustering analysis, the tested watermelon materials could be assigned into four groups, including tolerant, intermediate tolerant, moderately sensitive, and sensitive, respectively. The most drought-tolerant Citrullus germplasm, including 13 Citrullus lanatus var. lanatus and 12 C. lanatus var. citroides accessions, were originated from Africa. These genetic materials could be used for rootstock breeding or for developing drought-tolerant watermelon cultivars.
\end{abstract}

Watermelon, Citrullus lanatus Thunb. Matsum. \& Nakai, is an important vegetable fruit crop. China, with 68.2 million tons in production in 2009 , is currently the top watermelon producer with $67.7 \%$ of the world watermelon production (FAO, 2009). Most of the Chinese watermelon varieties were bred and selected for good performance under irrigated field conditions. Many are thus intolerant to drought stress. However, in recent years, drought has become a main abiotic stress on growth and productivity of watermelon. For example, the total production in Gansu province (China) declined $50 \%$ as a result of severe drought (Feng and $\mathrm{Wu}, 2007$ ). Drought-tolerant varieties, once developed, would be readily acceptable by the resourcepoor, rain-fed, and small holder farmers. A number of drought-tolerant varieties have been

Received for publication 31 May 2011. Accepted for publication 6 July 2011 .

This research was supported by the Beijing Municipal Science \& Technology Commission, China (Z09090501040902, D08070500690803, and 5100001); The Ministry of Science and Technology of the People's Republic of China (2009BADB8B02, 2010DFA54310, 30972015, and 2010AA10A107); and The Ministry of Agriculture of the People's Republic of China (CARS-26, 2007-Z9).

We thank Dr. Angela R. Davis of USDA-ARS, South Central Agriculture Research Lab, for her critical reviews to the manuscript.

${ }^{1}$ To whom reprint requests should be addressed; e-mail xuyong@nercv.org. developed for other crops (Fleury et al., 2010; Luigi et al., 2008), but only limited information is available for watermelon (Liu et al., 2008). Thus, identification of watermelon germplasm with drought tolerance properties is needed for the development of droughttolerant watermelon varieties. The National Engineering Research Center for Vegetables (NERCV) and the beijing academy of Agriculture and Forestry Science introduced $\approx 820$ randomly selected watermelon PI accessions from the Southern Regional Plant Introduction Station in Griffin, GA, in 2003 from the collection of $\approx 1600$ accessions. we previously conducted a detailed investigation on these valuable accessions and documented 12 important agronomic traits, including fruit shapes, soluble solid contents, and rind hardness, etc. (Fan et al., 2004). However, the nature of drought tolerance on these germplasm collecstudy, a large scale of 820 watermelon PI accessions and 246 breeding lines were evaluated for their drought tolerance properties on seedlings grown in the greenhouse under water stress conditions. The tolerance lines selected from these experiments could be valuable resources in watermelon breeding for drought tolerance.

\section{Materials and Methods}

Plant materials. A total of 1066 watermelon accessions were selected in the present study to determine their drought tolerance properties at the seedling stage under extreme tions has yet to be determined. In the present water stress conditions in an environmentally controlled greenhouse. Among them, 820 PI accessions were introduced from the Southern Regional Plant Introduction Station in Griffin, GA. These accessions originated from 57 different countries and represented three species, C. lanatus var. lanatus (766), C. lanatus var. citroides (53), and C. colocynthis (one). The other 246 watermelon cultivars or inbred lines (C. lanatus var. lanatus) were selected from watermelon breeding projects at the NERCV.

Seedling germination. Two independent replicated experiments were conducted to evaluate the drought tolerance properties on the preselected 1066 entries under water-stress conditions in Apr. to June 2007. In each experiment, 10 seedlings per entry were prepared. To ensure a uniform number of seedlings (10) per entry, extra (two to three) seeds were sown in each cell, 10 cells per entry on 50-cell nursery trays $(55 \mathrm{~cm} \times 28 \mathrm{~cm} \times 5 \mathrm{~cm}$; Zhejiang Jiahua Plastic Co., Zhejiang Province, China) filled with the potting matrix ( 3 peat:1vermiculite by volume). After pressing soil firmly to ensure uniformity in each cell, the nursery trays were watered thoroughly. On covering seeds with additional vermiculite, the trays were placed in an insect-free greenhouse with temperature at 15 to $25^{\circ} \mathrm{C}$ and natural lighting period of 14 to $16 \mathrm{~h}$ for proper seedling germination. Two layers of plastic film were placed on a flat ground to form a flat seed bed to prevent unnecessary root growing into and absorbing unwanted water from the ground. For each experiment, a total of 214 nursery trays were placed on the growth bed with $25 \mathrm{~m}$ in length and $1.3 \mathrm{~m}$ in width, which was covered with another layer of plastic film to maintain moisture. Seven days post-sowing, when $\approx 10 \%$ of seeds had germinated, the cover plastic film was removed and the trays were watered daily as needed to promote uniform seedling germination. When the first true leaf appeared, percent germination was recorded for each entry and plants were thinned to one seedling per cell to equalize plant number and to eliminate competition among plants in water-stress treatments.

Water-stress treatment. Water-stress treatment began when the seedlings reached the two- to three-true leaf stage. Before the treatment, soil in every cell on each tray was saturated by placing the nursery trays in a water container fully soaked for a couple of minutes to ensure uniformity of the soil moisture content in each cell. The first water-stress treatment on the pre-conditioned seedlings was conducted by having no watering or fertilizing for $4 \mathrm{~d}$. A general observation was carried out on the fifth day, at which point the soil moisture content in each cell was $\approx 2 \%$ (measured by Soil Moisture Monitoring 6050X3K1; Soil Moisture Equipment Corp., Santa Barbara, $\mathrm{CA}$ ) and $\approx 70 \%$ of the treated seedlings appeared to have permanent wilting symptoms (cotyledons curling downward and the first true leaves curling upward). Then all trays were thoroughly watered followed by a second water-stress treatment for 4 more $\mathrm{d}$. The final drought tolerance evaluation was conducted by careful examination of each 
individual seedling for their drought-induced injury symptoms on each accession according to the drought tolerance rating scales as determined in the following.

Retest of the drought-tolerant accessions. To examine whether such water-stress treatments on seedlings were reliable, a second independent experiment with a similar scale as described previously was repeated in the month immediately after the conclusion of the first experiment. Among them, the mean drought tolerance treatment ratings in the 175 entries of the drought-tolerant class in both experiments were determined along with their SDS.

Drought tolerance rating and ranking. Currently there is no uniform evaluation standard for drought tolerance on watermelon seedlings. In this study, based on the levels of severity in drought injury symptoms expressed on watermelon seedlings, we developed the following rating scales (Fig. 1), where $0=$ cotyledons and first true leaf remained in a normal horizontal position; $1=$ cotyledons pointed upward while the first true leaf remained horizontal; 3 = cotyledons curled downward and the first true leaf pointed upward; $5=$ cotyledons curled downward and the first true leaf curled upward; $7=$ whole plant showed desiccation. A mean drought tolerance rating was used to make the assessment to each accession on its drought tolerance property. The mean drought tolerance rating: $\mathrm{R}=\Sigma \mathrm{A} \times \mathrm{B} / \Sigma \mathrm{B}(\mathrm{A}=$ drought tolerance rating class, $\mathrm{B}=$ number of plant in each class) was calculated for each accession independently for each experiment. Finally, the drought tolerance status in all 1066 accessions was ranked using the mean figures for each accession based on the average of the mean drought tolerance ratings in two experiments and their SDS.

Cluster analysis. Cluster analysis is a common method for quantitative classification for large data sets, which has been widely used for classifying germplasm and genetic diversity (Galbraith et al., 2010). Clustering algorithms include two methods, hierarchical clustering and fast clustering (Carugo, 2010). The hierarchical clustering method was difficult to use as a result of large and variable data sets in the present study. Thus, the fast clustering method was more suitable for analysis of large samples (greater than 100) (Frades, 2010). The Fastclus dynamic clustering method in the SAS 9.1 System (SAS Institute Inc., 2004) was chosen. According to the protocol of the SAS 9.1 System, the number of sample clusters was predetermined manually based on the mean drought-tolerance ratings. Consequently, the 30 cluster categories pre-determined were analyzed by the computer software to classify the subclustered materials using the shortest distance principle until all samples were clustered into one of the four drought tolerance classes. Class 1 was for seedling plants in those accessions with drought tolerance $(R \leq 3.0)$. Class 2 was for accessions with intermediate tolerance ( $R=3.1$ to 5.0$)$ with small a SD among plants in the accession. Class 3 was for accessions with moderate sensitivity to water stress ( $R=3.1$ to 6.0$)$ with greater variation among plants. Class 4 was for accessions exhibiting sensitivity to water stress ( $R=6.1$ to 7.0$)$, meaning no drought tolerance for all plants in that accession.

\section{Results}

Primary screening. Using mean drought tolerance rating and their SD among seedling plants for each accession, the drought tolerance properties in the 1066 accessions evaluated in two independent and replicated experiments were divided into four general classes (Table 1).

Class 1, drought tolerance. Seedling plants in this group of accessions exhibited the highest tolerance to water stress treatment. After the treatment, seedling plants in this class showed normal appearance or exhibited water stress injury with symptoms less than 3.0. There were a total of 175 accessions in this class (Supplemental Table 1). Among them, the top 25 accessions with the highest

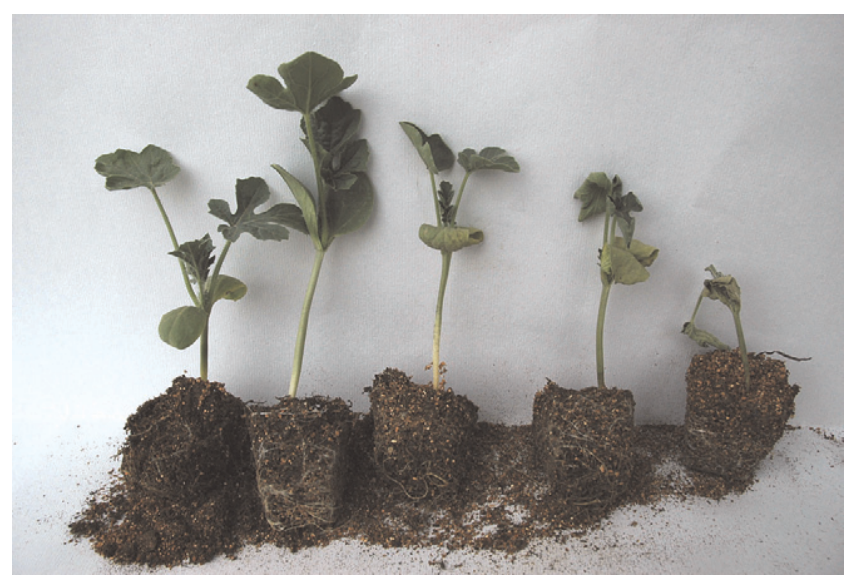

Fig. 1. Symptom expression on watermelon seedlings subjected to the water-stress treatment. From left to right, the drought tolerance rating scale determined from $0,1,3,5$, to 7 , where $0=$ cotyledons and first true leaf remained in a normal horizontal position; 1 = cotyledons pointed upward while the first true leaf remained horizontal; 3 = cotyledons curled downward and the first true leaf pointed upward; $5=$ cotyledons curled downward and the first true leaf curled upward; $7=$ the whole plant showed desiccation. level of drought tolerance $(R \leq 1.0)$ included 12 accessions of the wild watermelon of $C$. lanatus var. citroides and 13 accessions of C. lanatus var. lanatus. Interestingly, 24 of the total 25 strongest drought tolerant accessions were originally collected in Africa (Table 2).

Class 2, intermediate drought-tolerant. There were a total of 257 accessions assigned to this class (Table 1). after the water stress treatment, seedling plants in this group of accessions exhibited water stress injury symptoms ranging from 3.1 to 5.0. In general, seedling plants in this group showed some levels of water stress injury (cotyledons curled downward and the first true leaf pointed or curled upward) (Fig. 1). among the 257 accessions in this class, 30 were from watermelon breeding lines with fair agronomic characters or disease resistance. Thus, these lines could be used directly in the development of droughttolerant watermelon cultivars.

Class 3, moderately sensitive to drought. There were 262 accessions assigned to this class. Seedling plants in this class showed drought injury symptoms with mean drought tolerance ratings $3.1 \leq R<6.0$. Plants in this class also showed the most variation in their responses to the water stress treatment, resulting in greater SDs among plants in drought tolerance rating within an individual accession.

Class 4, sensitive to drought. This class consisted of accessions with seedling plants displaying strong sensitivity to water stress with drought tolerance ratings ranging from 6.1 to 7.0. There were a total of 372 accessions assigned to this class (Table 1). After drought stress treatment, most of them displayed drought injury symptoms with severe leaf deformation and stunted plant growth (Fig. 1).

Reliability of the water-stress treatment for drought-tolerance evaluation. To determine the reliability of the water-stress treatment for drought-tolerance evaluation in seedlings as observed in the first trial, a second independent experiment was conducted and their drought tolerance ratings in the first 175 most drought tolerance accessions were compared (Supplemental Table 1). Their sDs between the two experiments in drought-tolerance ratings were calculated. In general, the ratings on the drought tolerance in both experiments were in good agreement, especially in the 175 drought tolerance accessions $(\mathrm{SD}<0.4)$. Ranked in the top in drought tolerance were 25 accessions with a mean tolerance rating of 1.0 or less in both experiments (Table 2).

Cluster analysis. In the present study, different genotypes displayed a wide range of drought tolerance responses in seedlings to water stress, suggesting wide genetic variability. The 30 cluster categories, first predefined manually for the 1066 accessions according to the levels of drought tolerance, were analyzed with the Fastclus program. when distance between cluster average points was set to 0.70 , the 30 clusters could be divided into four classes: 1 to 4 . They were used to classify their drought-tolerance properties (Table 1). Class 1 with the most tolerance to water stress contained clusters Nos. 5, 25, and 28. This class included the 25 accessions from No. 25 cluster, 
Table 1. The drought tolerance properties of the 820 USDA Citrullus germplasm accessions and 246 local watermelon breeding lines as evaluated with waterstress treatments on seedlings in a greenhouse.

\begin{tabular}{|c|c|c|c|c|c|c|c|c|c|}
\hline \multirow[b]{2}{*}{ Class $^{z}$} & \multirow[b]{2}{*}{ Cluster ${ }^{y}$} & \multirow{2}{*}{$\begin{array}{c}\text { No. of } \\
\text { accessions in } \\
\text { that cluster }\end{array}$} & \multirow[b]{2}{*}{$R^{\mathrm{x}}$} & \multirow{2}{*}{$\begin{array}{l}\text { Representative } \\
\text { accession in } \\
\text { that cluster }\end{array}$} & \multicolumn{5}{|c|}{ No. of plants with symptoms in each rating scale for the representative accession } \\
\hline & & & & & $0^{\mathrm{w}}$ & $1^{\mathrm{w}}$ & $3^{\mathrm{w}}$ & $5^{\mathrm{w}}$ & $7^{\mathrm{w}}$ \\
\hline I & 25 & 25 & $0.9-1.0$ & PI 271983 & 1 & 9 & 0 & 0 & 0 \\
\hline I & 5 & 141 & $1.2-2.0$ & PI 171586 & 0 & 6 & 4 & 0 & 0 \\
\hline I & 28 & 9 & $2.4-3.0$ & PI 476330 & 0 & 3 & 7 & 0 & 0 \\
\hline II & 8 & 7 & $3.2-3.4$ & PI 296343 & 0 & 0 & 9 & 1 & 0 \\
\hline II & 13 & 4 & $3.4-3.6$ & PI 165002 & 0 & 0 & 8 & 2 & 0 \\
\hline II & 7 & 11 & $3.6-3.8$ & PI 512828 & 0 & 0 & 7 & 3 & 0 \\
\hline II & 26 & 31 & $3.8-4.2$ & PI 370434 & 0 & 0 & 5 & 5 & 0 \\
\hline II & 6 & 65 & $4.0-4.2$ & PI 379229 & 0 & 0 & 4 & 6 & 0 \\
\hline II & 17 & 8 & $4.2-4.4$ & PI 482278 & 0 & 0 & 3 & 7 & 0 \\
\hline II & 20 & 53 & $4.4-4.8$ & PI 169280 & 0 & 0 & 2 & 7 & 1 \\
\hline II & 3 & 12 & $4.6-4.8$ & PI 479704 & 0 & 0 & 1 & 9 & 0 \\
\hline II & 4 & 64 & $4.8-5.0$ & Grif 1732 & 0 & 0 & 0 & 10 & 0 \\
\hline II & 24 & 2 & $4.6-4.8$ & PI 368500 & 0 & 0 & 2 & 8 & 0 \\
\hline III & 10 & 62 & $3.2-3.8$ & PI 177324 & 0 & 1 & 7 & 1 & 1 \\
\hline III & 30 & 14 & $3.2-3.6$ & PI 379232 & 0 & 1 & 8 & 0 & 1 \\
\hline III & 11 & 30 & $3.4-3.6$ & Grif 12335 & 0 & 0 & 8 & 1 & 1 \\
\hline III & 22 & 25 & $3.6-4.2$ & PI 172786 & 0 & 0 & 6 & 2 & 2 \\
\hline III & 19 & 6 & $3.6-4.2$ & PI 295850 & 0 & 2 & 4 & 2 & 2 \\
\hline III & 15 & 23 & $3.8-4.2$ & PI 169251 & 0 & 0 & 5 & 4 & 1 \\
\hline III & 29 & 14 & $3.8-4.4$ & PI 164709 & 0 & 0 & 6 & 2 & 2 \\
\hline III & 16 & 34 & $4.0-4.6$ & PI 482305 & 0 & 0 & 6 & 0 & 4 \\
\hline III & 27 & 20 & $4.2-5.2$ & PI 164685 & 0 & 1 & 4 & 3 & 2 \\
\hline III & 23 & 8 & $4.5-5.2$ & PI 534533 & 0 & 0 & 4 & 1 & 5 \\
\hline III & 2 & 3 & $4.6-4.8$ & PI 278048 & 0 & 0 & 3 & 6 & 1 \\
\hline III & 9 & 11 & $4.8-5.8$ & PI 229806 & 0 & 0 & 5 & 0 & 5 \\
\hline III & 14 & 6 & $5.2-5.4$ & PI 162667 & 0 & 0 & 2 & 5 & 3 \\
\hline III & 18 & 6 & $5.2-5.8$ & PI 163205 & 0 & 0 & 2 & 3 & 5 \\
\hline IV & 12 & 5 & $6.1-6.4$ & PI 381734 & 0 & 0 & 2 & 0 & 8 \\
\hline IV & 21 & 54 & $6.4-6.8$ & Grif 1730 & 0 & 0 & 0 & 2 & 8 \\
\hline IV & 1 & 313 & $6.8-7.0$ & Grif 1729 & 0 & 0 & 0 & 0 & 10 \\
\hline
\end{tabular}

${ }^{2}$ Using the Fastclus program analysis, 30 cluster categories were divided into 4 classes: I to IV, where I = drought-tolerant group, normal appearance or their injury symptom ratings $R<3.0$; II = intermediate drought-tolerant group, their symptom ratings were $R=3.1-5.0$; III = moderately sensitive to drought group, seedling injury symptoms in $R=3.1-6.0$ with greater SD in their responses to drought stress among plants within each accession; IV = sensitive to drought group, most of them demonstrated severe injury symptoms with $R=6.1-7.0$.

${ }^{y}$ Using the Fastclus dynamic clustering method, the 30 cluster categories were predefined manually. Then according to their similarity in the response to drought stress treatment, the computer program was used to classify the subclustered materials using the shortest distance principle until all samples were clustered.

${ }^{x}$ The mean drought tolerance rating: $R=\Sigma \mathrm{A} \times \mathrm{B} / \Sigma \mathrm{B}(\mathrm{A}=$ drought tolerance rating class; $\mathrm{B}=$ number of plants in each class).

${ }^{\mathrm{w}}$ Drought reaction for all PIs and breeding lines was rated on a $0,1,3,5,7$ scale, where $0=$ cotyledons and first true leaf remained in a normal horizontal position; $1=$ cotyledons pointed upward while the first true leaf remained horizontal; $3=$ cotyledons curled downward and the first true leaf pointed upward; $5=$ cotyledons curled downward and the first true leaf curled upward; $7=$ the whole plant showed desiccation. There were 10 plants in each accession.

which demonstrated the highest level of drought tolerance. Twelve of these accessions belonged to $C$. lanatus var. citroides, the wild watermelon, and 13 other accessions in C. lanatus var. lanatus. Class 2, intermediate tolerance, included cluster Nos. 3, 4, 6 to 8, 13, 17, 20, 24, and 26. Class 3, with moderate drought sensitivity, contained accessions in the cluster Nos.1, 12, and 21. Class 4, the most sensitive to water stress, consisted of 14 clusters in Nos. 2, 9 to 11 , 14 to $16,18,19,22,23,27,29$, and 30 .

\section{Discussion}

In the present study, we evaluated a total of 1066 accessions of watermelon germplasm for their responses to drought tolerance through the use of water stress on seedlings under greenhouse conditions. Among the 175 accessions in the drought tolerance class, the top 25 accessions contained those collections of $C$. lanatus var. citroides that were originally collected in the desert areas in Africa. Our test results here confirmed their drought tolerance properties. In fact, seedlings from these drought-tolerant lines were transplanted to field-growing conditions in the tropical
Hainan Island, China. Even without any additional irrigation, just through the natural rain-fed conditions, these drought-tolerant plants were capable of growing to maturity, whereas other control watermelon cultivars could not survive in the field (data not shown).

Drought is by far the most important environmental stress for agriculture and many efforts have been made to improve crop productivity under water-limited conditions (Bartels and Sunkar, 2005). However, there is no standard method in drought-stress screening. Several factors limit the reliability of such test, including the number of plants, land size required, climate, and stress severity (Condon et al., 2004). Pot cultivation method has been adapted in the previous studies (Liu et al., 2008) to evaluate numerous local watermelon germplasm for their drought tolerance. With pot cultivation, it is difficult to ensure the uniformity of soil moisture content among pots. The space limitation also prohibits evaluation of more than 50 accessions. Therefore, it will not be feasible to adapt this method for our screening of more than 1000 accessions. Therefore, we had to develop a new system that would permit an efficient evaluation of thou- sands of accessions. The drought tolerance rating system appeared to be robust and the data were repeatable between two independent experiments. The water-stress treatment on seedlings in the greenhouse was successfully used to screen 1066 watermelon accessions.

Among the top 25 accessions with the most drought tolerance of $C$. lanatus var. citroides accessions, several of them were also shown to have virus resistance. For example, PI 244018 is resistant to papaya ringspot virus type-W (Strange et al., 2002) and PI 482308 is resistant to zucchini yellow mosaic virus (Ling and Levi, 2007). These two accessions were also shown to have strong drought tolerance in the present study, which might be useful materials in gene pyramiding.

In studies of gene expression in wild watermelon under drought conditions, higher concentrations of citrulline, glutamate, and arginine could be accumulated in watermelon leaves (Akashi et al., 2001, 2004; Yokota et al., 2002). Si et al. (2009) identified several drought-responsive genes using cDNAamplified fragment length polymorphism. The expression patterns of these drought-responsive genes under drought stress and hormone 
Table 2. Comparative drought tolerance ratings of the top twenty five most drought-tolerant Citrullus accessions.

\begin{tabular}{|c|c|c|c|c|c|}
\hline Rank & Accessions & Mean $R^{\mathrm{z}}$ & SD & Species $^{\mathrm{y}}$ & Seed source \\
\hline 1 & PI 559995 & 0.85 & 0.05 & $\mathrm{~L}$ & Nigeria \\
\hline 2 & PI 482246 & 0.90 & 0.00 & $\mathrm{C}$ & Zimbabwe \\
\hline 3 & PI 482312 & 0.90 & 0.00 & $\mathrm{C}$ & Zimbabwe \\
\hline 4 & PI 271983 & 0.90 & 0.10 & $\mathrm{~L}$ & Somalia \\
\hline 5 & PI 482285 & 0.90 & 0.10 & $\mathrm{~L}$ & Zimbabwe \\
\hline 6 & PI 500309 & 0.90 & 0.10 & $\mathrm{~L}$ & Zambia \\
\hline 7 & PI 482287 & 0.95 & 0.05 & $\mathrm{~L}$ & Zimbabwe \\
\hline 8 & PI 379246 & 0.95 & 0.05 & $\mathrm{~L}$ & Former Yugoslavia \\
\hline 9 & PI 482311 & 0.95 & 0.05 & $\mathrm{C}$ & Zimbabwe \\
\hline 10 & PI 482274 & 0.95 & 0.05 & $\mathrm{~L}$ & Zimbabwe \\
\hline 11 & PI 482316 & 0.95 & 0.05 & $\mathrm{C}$ & Zimbabwe \\
\hline 12 & PI 482283 & 0.95 & 0.05 & $\mathrm{C}$ & Zimbabwe \\
\hline 13 & PI 482270 & 1.00 & 0.00 & $\mathrm{~L}$ & Zimbabwe \\
\hline 14 & PI 500327 & 1.00 & 0.00 & $\mathrm{~L}$ & Zambia \\
\hline 15 & PI 482304 & 1.00 & 0.00 & $\mathrm{~L}$ & Zimbabwe \\
\hline 16 & PI 500332 & 1.00 & 0.00 & $\mathrm{C}$ & Zambia \\
\hline 17 & PI 482302 & 1.00 & 0.00 & $\mathrm{C}$ & Zimbabwe \\
\hline 18 & PI 271984 & 1.00 & 0.00 & $\mathrm{~L}$ & Somalia \\
\hline 19 & PI 482308 & 1.00 & 0.00 & $\mathrm{C}$ & Zimbabwe \\
\hline 20 & PI 482309 & 1.00 & 0.00 & $\mathrm{C}$ & Zimbabwe \\
\hline 21 & PI 482310 & 1.00 & 0.00 & $\mathrm{~L}$ & Zimbabwe \\
\hline 22 & PI 482327 & 1.00 & 0.00 & $\mathrm{~L}$ & Zimbabwe \\
\hline 23 & PI 500335 & 1.00 & 0.00 & $\mathrm{C}$ & Zambia \\
\hline 24 & PI 482303 & 1.00 & 0.00 & $\mathrm{C}$ & Zimbabwe \\
\hline 25 & PI 482307 & 1.00 & 0.00 & $\mathrm{C}$ & Zimbabwe \\
\hline
\end{tabular}

zThe mean drought tolerance rating based on two experiments: $R=\Sigma \mathrm{A} \times \mathrm{B} / \Sigma \mathrm{B}(\mathrm{A}=$ drought tolerance rating class; $\mathrm{B}=$ number of plants in each class).

${ }^{\mathrm{y}} \mathrm{L}=\mathrm{C}$. lanatus var. lanatus; $\mathrm{C}=$ C. lanatus var. citroides.

treatment show promise in the improvement of watermelon for drought tolerance.

Some morphological traits may also be related to the drought tolerance, for example, stronger root and thicker leaf. Liu et al. (2008) have compared the growth and physiological characteristics of seven watermelon varieties and their parents in pots (artificial drought stress) and gravel-mulched field; they found some germplasm with weak tolerance at the seedling stage but with moderate tolerance at the mature stage. This is likely because of the strong root system would permit the mature plants to absorb water from a deeper soil layer. We will continue to evaluate these promising materials to further select drought-tolerant lines with good agronomic traits and high yields under field conditions.

The result in the present study demonstrates that there is significant tolerance to drought
Carugo, O. 2010. Clustering criteria and algorithms. Methods Mol. Biol. 609:175-196.

Condon, A.G., R.A. Richards, G.J. Rebetzke, and G.D. Farquhar. 2004. Breeding for high wateruse efficiency. J. Expt. Bot. 55:2447-2460.

Fan, M., G.Y. Gong, R.L. Zhang, and Y. Xu. 2004 Quantitative assessment of American watermelon germplasm. China Watermelon and Melon 4:1-3 [in Chinese with English summary].

FAO of the United Nations. 2009. Food and agricultural commodities production. 10 May 2011. $<$ http://faostat.fao.org/site/339/default.aspx $>$.

Feng, X.H. and D.K. Wu. 2007. Planting cucurbits in gravel mulched land. China Cucurbits and Vegetables 1:57-58 [in Chinese].

Fleury, D., S. Jerreries, H. Kuchel, and P. Langridge. 2010. Genetic and genomic tools to improve drought tolerance in wheat. J. Expt. Bot. 61: 3211-3222.

Frades, I.R. 2010. Overview on techniques in cluster analysis. Methods Mol. Biol. 593:81-107.

Galbraith, S., J.A. Daniel, and B. Vissel. 2010. A study of clustered data and approaches to its analysis. J. Neurosci. 30:10601-10608.

Ling, K.-S. and A. Levi. 2007. Sources of resistance to Zucchini yellow mosaic virus in Lagenaria siceraria germplasm. HortScience 42:11241126.

Liu, D.S., W.B. Yang, and X.Q. Zhao. 2008. Studies on watermelon drought tolerance identification indices and method in gravel-mulched land of northwest China. China Vegetables. 7:17-21 [in Chinese with English summary].

Luigi, C., F. Rizza, F.W. Badeck, E. Mazzucotelli, A.M. Mastrangelo, E. Francia, C. Mare, A. Tondelli, and A.M. Stanca. 2008. Drought tolerance improvement in crop plants: An integrated view from breeding to genomics. Field Crops Res. 105:1-14.

SAS Institute Inc. 2004. SAS/STAT 9.1 user's guide. SAS Institute Inc., Cary, NC. p. $1377-$ 1427.

Si, Y., C.K. Zhang, S.S. Meng, and F. Dane. 2009. Gene expression changes in response to drought stress in Citrullus colocynthis. Plant Cell Rep. 28:997-1009.

Akashi, K., C. Miyake, and A. Yokota. 2001. Citrulline, a novel compatible solute in drought-tolerance wild watermelon leaves, is an efficient hydroxyl radical scavenger. FEBS Lett. 508:438-442.

Akashi, K., N. Nishimura, Y. Ishida, and A. Yokota. 2004. Potent hydroxyl radical-scavenging activity of drought-induced type-2 metallothionein in wild watermelon. Biochem. Biophys. Res. Commun. 323:72-78.

Bartels, D. and R. Sunkar. 2005. Drought and salt tolerance in plants. Crit. Rev. Plant Sci. 24:23-58.
Strange, E.B., N. Guner, Z. Pesic-VanEsbroeck, and T.C. Wehner. 2002. Screening the watermelon germplasm collection for resistance to Papaya ringspot virus type-W. Crop Sci. 42:1324 1330.

Yokota, A., S. Kawasaki, M. Iwano, C. Nakamura, C. Miyake, and K. Akashi. 2002. Citrulline and DRIP-1 protein (ArgE homologue) in drought tolerance of wild watermelon. Ann. Bot. (Lond.) $89: 825-832$. 

experiments.

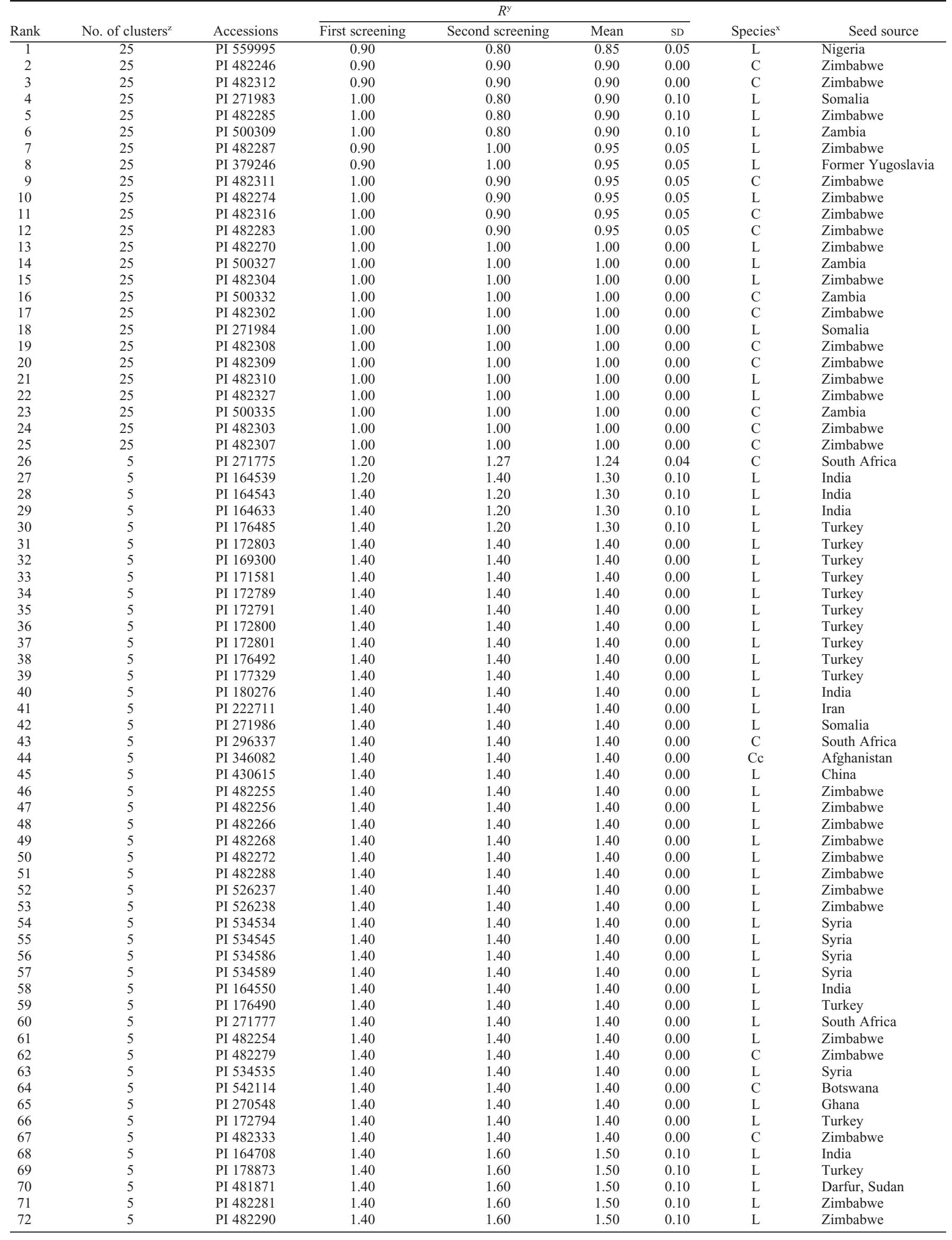



between two experiments.

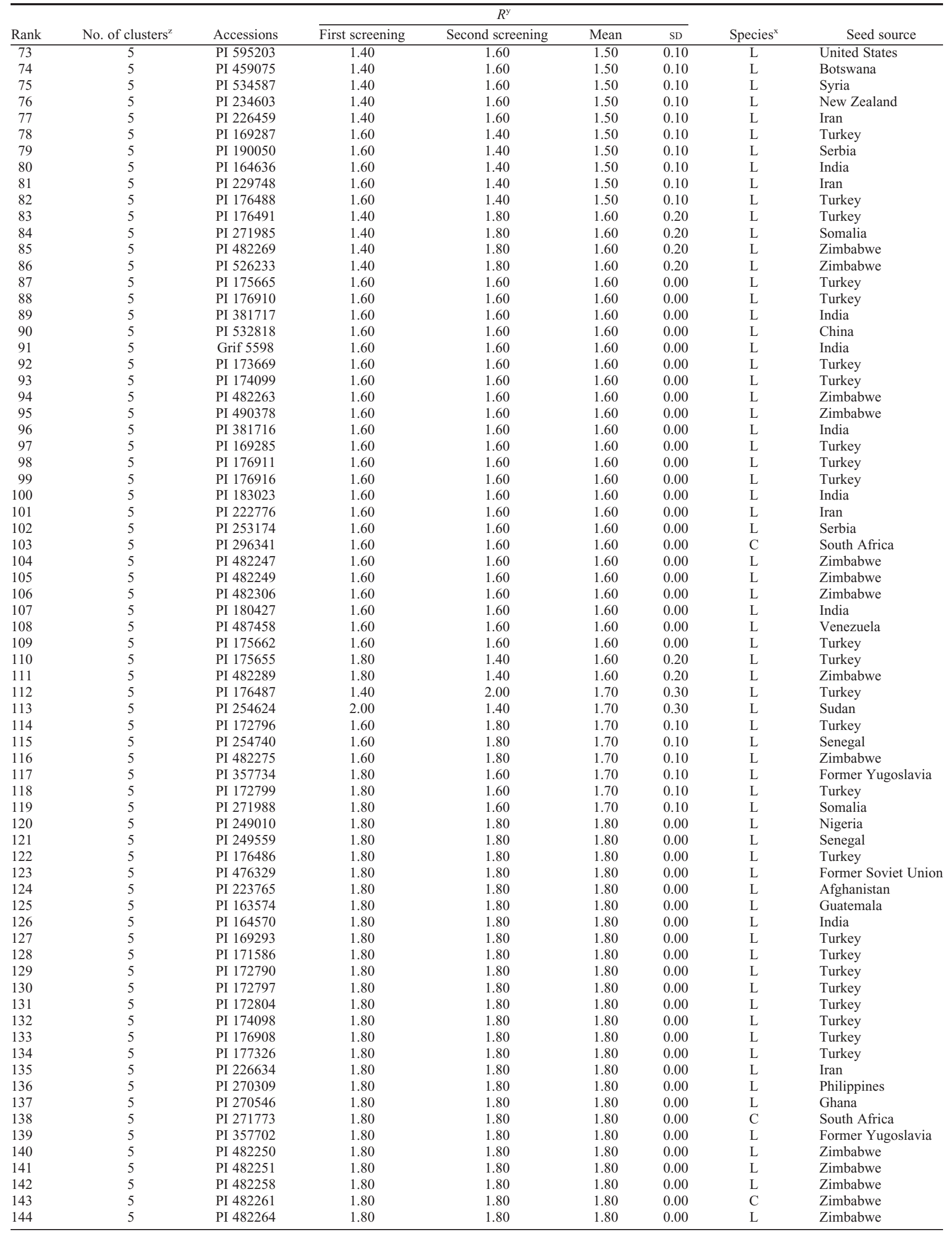


Supplemental Table 1. (Continued) Comparative analyses to the first 175 most drought-tolerant Citrullus accessions for their responses to water stress treatments between two experiments.

\begin{tabular}{|c|c|c|c|c|c|c|c|c|}
\hline \multirow[b]{2}{*}{ Rank } & \multirow[b]{2}{*}{ No. of clusters ${ }^{z}$} & \multirow[b]{2}{*}{ Accessions } & \multicolumn{4}{|c|}{$R^{\mathrm{y}}$} & \multirow[b]{2}{*}{ Species $^{\mathrm{x}}$} & \multirow[b]{2}{*}{ Seed source } \\
\hline & & & First screening & Second screening & Mean & SD & & \\
\hline$\overline{145}$ & 5 & PI 482271 & 1.80 & 1.80 & 1.80 & 0.00 & $\mathrm{~L}$ & Zimbabwe \\
\hline 146 & 5 & PI 490375 & 1.80 & 1.80 & 1.80 & 0.00 & $\mathrm{~L}$ & Zimbabwe \\
\hline 147 & 5 & PI 505593 & 1.80 & 1.80 & 1.80 & 0.00 & $\mathrm{~L}$ & Zambia \\
\hline 148 & 5 & PI 532624 & 1.80 & 1.80 & 1.80 & 0.00 & $\mathrm{C}$ & Zimbabwe \\
\hline 149 & 5 & PI 534588 & 1.80 & 1.80 & 1.80 & 0.00 & $\mathrm{~L}$ & Syria \\
\hline 150 & 5 & PI 176922 & 2.00 & 1.80 & 1.90 & 0.10 & $\mathrm{~L}$ & Turkey \\
\hline 151 & 5 & PI 482265 & 2.00 & 1.80 & 1.90 & 0.10 & $\mathrm{C}$ & Zimbabwe \\
\hline 152 & 5 & PI 175656 & 2.00 & 2.00 & 2.00 & 0.00 & $\mathrm{~L}$ & Turkey \\
\hline 153 & 5 & PI 482277 & 2.00 & 2.00 & 2.00 & 0.00 & $\mathrm{C}$ & Zimbabwe \\
\hline 154 & 5 & PI 164146 & 2.00 & 2.00 & 2.00 & 0.00 & $\mathrm{~L}$ & India \\
\hline 155 & 5 & PI 169286 & 2.00 & 2.00 & 2.00 & 0.00 & $\mathrm{~L}$ & Turkey \\
\hline 156 & 5 & PI 169295 & 2.00 & 2.00 & 2.00 & 0.00 & $\mathrm{~L}$ & Turkey \\
\hline 157 & 5 & PI 177327 & 2.00 & 2.00 & 2.00 & 0.00 & $\mathrm{~L}$ & Turkey \\
\hline 158 & 5 & PI 178872 & 2.00 & 2.00 & 2.00 & 0.00 & $\mathrm{~L}$ & Turkey \\
\hline 159 & 5 & PI 186975 & 2.00 & 2.00 & 2.00 & 0.00 & $\mathrm{~L}$ & Ghana \\
\hline 160 & 5 & PI 195562 & 2.00 & 2.00 & 2.00 & 0.00 & $\mathrm{~L}$ & Ethiopia \\
\hline 161 & 5 & PI 254736 & 2.00 & 2.00 & 2.00 & 0.00 & $\mathrm{~L}$ & Senegal \\
\hline 162 & 5 & PI 505594 & 2.00 & 2.00 & 2.00 & 0.00 & $\mathrm{~L}$ & Zambia \\
\hline 163 & 5 & PI 171580 & 2.00 & 2.00 & 2.00 & 0.00 & $\mathrm{~L}$ & Turkey \\
\hline 164 & 5 & PI 296342 & 2.00 & 2.00 & 2.00 & 0.00 & $\mathrm{C}$ & South Africa \\
\hline 165 & 5 & PI 189316 & 2.09 & 2.09 & 2.09 & 0.00 & $\mathrm{~L}$ & Nigeria \\
\hline 166 & 5 & PI 176489 & 2.00 & 2.20 & 2.10 & 0.10 & $\mathrm{~L}$ & Turkey \\
\hline 167 & 28 & PI 169288 & 2.40 & 2.40 & 2.40 & 0.00 & $\mathrm{~L}$ & Turkey \\
\hline 168 & 28 & PI 169292 & 2.40 & 2.60 & 2.50 & 0.10 & $\mathrm{~L}$ & Turkey \\
\hline 169 & 28 & PI 476330 & 2.40 & 2.80 & 2.60 & 0.20 & $\mathrm{~L}$ & Former Soviet Union \\
\hline 170 & 28 & PI 534584 & 2.60 & 2.60 & 2.60 & 0.00 & $\mathrm{~L}$ & Syria \\
\hline 171 & 28 & PI 534593 & 2.60 & 2.60 & 2.60 & 0.00 & $\mathrm{~L}$ & Syria \\
\hline 172 & 28 & PI 500337 & 2.40 & 3.20 & 2.80 & 0.40 & $\mathrm{~L}$ & Zambia \\
\hline 173 & 28 & PI 482337 & 2.80 & 2.80 & 2.80 & 0.00 & $\mathrm{~L}$ & Zimbabwe \\
\hline 174 & 28 & PI 482298 & 3.00 & 3.00 & 3.00 & 0.00 & $\mathrm{C}$ & Zimbabwe \\
\hline 175 & 28 & PI 482335 & 3.00 & 3.00 & 3.00 & 0.00 & $\mathrm{C}$ & Zimbabwe \\
\hline
\end{tabular}

${ }^{\mathrm{z}}$ Using the Fastclus dynamic clustering method, the 30 cluster categories were predefined manually. Then according to their similarity in responses to drought stress treatment, the computer software was used to classify the subclustered materials using the shortest distance principle until all samples were clustered. ${ }^{y}$ The mean drought tolerance rating: $R=\Sigma \mathrm{A} \times \mathrm{B} / \Sigma \mathrm{B}(\mathrm{A}=$ drought tolerance rating class; $\mathrm{B}=$ number of plants in each class).

${ }^{\times} \mathrm{L}=$ C. lanatus var. lanatus $; \mathrm{C}=C$. lanatus var. citroides $; \mathrm{Cc}=$ C. colocynthis. 